\title{
Determination of Trace Elements and Human Health Risk Assessment in Bottled Spring Water: Method Validation
}

\author{
Serpil Kilic* and Murat Kilic \\ Akdeniz University, Food Safety and Agricultural Research Center, 07058, Antalya, Turkey
}

\section{INTRODUCTION}

Natural spring waters are probably one of the most important resources on earth. Springs located in the mountains provide waters of the highest mineralization. Today, thousands of people consume bottled spring water (1). Due to the importance of elements in the human metabolism, elemental analysis is a major part of general health studies, since exposure to toxic metals can significantly affect human health. According to the United States Environmental Protection Agency (USEPA) and the International Agency for Research on Cancer (IARC), these metals are also classified as human carcinogens based on epidemiological evidence (2).

The metal ingredients of spring water may vary due to the conditions of the geological and climatic characteristics of the place of production, $\mathrm{pH}$, and conductivity. The reality of the possibility of having different metal ingredients resulting from the conditions of production in addition to the production area makes determination of the metal ingredients in the mentioned products necessary (3-4). Thus, monitoring metal concentrations in bottled spring water is of considerable importance.

The measurement methods used to determine toxic metals in beverages are inductively coupled plasma atomic emission spectrometry (ICP-AES) (5) and inductively coupled plasma mass spectrometry (ICP-MS) (6-10). When compared

\footnotetext{
*Corresponding autbor.

E-mail: serpilkilic@akdeniz.edu.tr

E-mail: serpil.a.kilic@gmail.com
}

Tel: +90 (242) 2274400-2585

\begin{abstract}
Water is necessary for all life and contains minerals which play a major role in the human diet. This study monitors the elemental composition of different brands of bottled spring water marketed in Turkey and discusses the compositional parameters. Spring water samples were analyzed for cesium (Cs), rubidium ( $\mathrm{Rb})$, thallium (Tl), cobalt (Co), arsenic (As), chromium (Cr), lead $(\mathrm{Pb})$, gallium (Ga), vanadium (V), silver (Ag), cadmium (Cd), uranium (U), thorium (Th), and molybdenum (Mo) by inductively coupled plasma mass spectrometry (ICP-MS).

Method accuracy was confirmed by using the SRM 1640A Natural Water certified reference material. The linearity, limit of detection, limit of quantification, repeatability, and recovery (\%) were assessed. According to the results of the spring water analysis, Cd, Cs, Tl, Co, Pb, Ag, and Th were not detected in the samples. However, Rb, As, Cr, Ga, U and Mo were detected in some samples. The results were compared with elemental standards for drinking waters set according to the World Health Organization (WHO) and the European Union (EU). The results obtained were compared with permissible levels of Estimated Daily Intake (EDI), Target Hazard Quotient (THQ), and Hazard Index (HI). The THQ values less than 1 show that there is no major risk of carcinogenic effects to those exposed.
\end{abstract}

with other techniques, the advantages of ICP-MS include high sensitivity, low limits of detection, and multi-elemental capability.
The aim of this study was to establish and validate an analytical method for the determination of $\mathrm{Cs}, \mathrm{Rb}, \mathrm{Tl}, \mathrm{Co}, \mathrm{As}, \mathrm{Cr}, \mathrm{Pb}, \mathrm{Ga}, \mathrm{V}$, $\mathrm{Ag}, \mathrm{Cd}, \mathrm{U}, \mathrm{Th}$, and Mo in different spring waters using ICP-MS. A simple and efficient method is described, including sample preparation. The results were compared with WHO guidelines, and the levels of the elements at which they can cause risk to human health are identified. The performance characteristics of this method, including linearity, limit of detection (LOD), limit of quantification (LOQ), specificity/selectivity, and recovery (\%), were determined. Also, the results obtained were checked against permissible levels, daily intake, target hazard quotient, and hazard index.

\section{EXPERIMENTAL}

\section{Sample Preparation}

Twenty-two bottled waters (500 $\mathrm{mL}$ of water, $19 \mathrm{~L}$ in dispenser size bottled water) of different brands and sources were bought on the market in Turkey during 2019 (Figure 1). The bottles were opened at the moment of sample preparation, and the samples diluted to $50 \mathrm{~mL}$ by using $2 \%$ (v/v) $\mathrm{HNO}_{3}$ solution, then analyzed by ICP-MS.

\section{Standard Solutions Preparation \\ Stock calibration standard solu- tions $(10 \mathrm{mg} / \mathrm{L})$ of the elements were prepared in $2 \% \mathrm{HNO}_{3}(\mathrm{VHG}$, USA). Suprapur ${ }^{\circledR}$ concentrated nitric acid $\left(\mathrm{HNO}_{3}, 65 \%\right)$ was obtained from Merck (Germany). Deionized water was obtained using a Milli-Q ${ }^{\circledR}$ ultrapure water purification system (Millipore Cor- poration, USA).}


Instrumentation

A Model ELAN ${ }^{\circledR}$ DRC $^{\text {TM }}$-e ICP-MS was used for the determination of Cs, Rb, Tl, Co, As, Cr, Pb, Ga, V, Ag, Cd, U, Th, and Mo (PerkinElmer, Inc., Shelton, CT, USA). The optimized results of the ICP-MS are summarized in Table I.

\section{Analytical Methods}

Several parameters were taken into account and evaluated for method validation, including linear range, recovery at three levels (minimum, medium and maximum), LOD (limit of detection), LOQ (limit of quantification), trueness by CRM (certified reference material), and repeatability. Analytical method validation of the ICP-MS for the determination of the elements was applied in accordance with the Eurachem guide (11). This approach can be considered a simple application of the step-by-step approach. The certified reference material NIST 1640 Natural Water (National Institute of Standards and Technologuy, USA) was used for this study.

\section{Health Risk Assessment}

The estimated daily intake (EDI) of toxic metal was determined by using Eq. (1) as reported in the literature (12).

(Eq. 1) Conc. of toxic metals in food $\mathrm{x}$ Mean food intake

Daily Intake =

(EDI)

Body Weight

The dietary intake of toxic metals considered in this study were checked using the provisional tolerable weekly intake (PTWI) as per JECFA (Joint FAO/WHO Expert Committee on Food Additives) (13). The Target Hazard Quotient was obtained using the following USEPA equation (14):

$$
\mathrm{THQ}=\frac{(\text { Eq. } 2)}{\text { RfD } \times \mathrm{BW} \times \mathrm{AT}} \times 10^{-3}
$$

TABLE I

\begin{tabular}{|c|c|}
\hline Spectrometer & ELAN $^{\circledR}{ }^{\circledR}$ DRC $^{\text {TM }}$-e ICP-MS \\
\hline Sample Introduction & Ryton ${ }^{\circledR}$ Scott Spray Chamber \\
\hline RF Power & $1000 \mathrm{~W}$ \\
\hline Skimmer Cone & Nickel \\
\hline \multicolumn{2}{|l|}{ Gas flow rates: } \\
\hline Nebulizer gas flow & $0.91 \mathrm{~L} \mathrm{~min}^{-1}$ \\
\hline Auxillary gas flow & $1.20 \mathrm{~L} \mathrm{~min}^{-1}$ \\
\hline Plasma gas flow & $17 \mathrm{~L} \mathrm{~min}^{-1}$ \\
\hline Lens voltage & 6.50 Volt \\
\hline Autolens voltage & $\begin{array}{l}{ }^{9} \mathrm{Be} 5.7 \text { Volt, }{ }^{59} \mathrm{Co} 6.5 \text { Volt, }{ }^{115 \mathrm{In}} 7.0 \text { Volt, } \\
{ }^{238} \mathrm{U} 9.0 \text { Volt }\end{array}$ \\
\hline Nebulizer & Meinhard $^{\circledR}$ TQ plus Quartz $0.5 \mathrm{~mL}$ \\
\hline Scanning mode & Peak hopping \\
\hline Analytical masses (amu) & $\begin{array}{l}\text { Standard mode }{ }^{133} \mathrm{Cs},{ }^{85} \mathrm{Rb},{ }^{205} \mathrm{Tl},{ }^{59} \mathrm{Co}, \\
{ }^{75} \mathrm{As},{ }^{52} \mathrm{Cr},{ }^{208} \mathrm{~Pb},{ }^{69} \mathrm{Ga},{ }^{51} \mathrm{~V},{ }^{10} 7 \mathrm{Ag},{ }^{111} \mathrm{Cd}, \\
{ }^{238} \mathrm{U},{ }^{232} \mathrm{Th},{ }^{98} \mathrm{Mo}\end{array}$ \\
\hline Number of sweeps/reading & 20 \\
\hline Number of readings/replicate & 1 \\
\hline Number of replicates & 3 \\
\hline Autosampler & CETAC $^{\circledR}$ ASX-520 \\
\hline Dwell time per AMU & $50 \mathrm{~ms}$ \\
\hline Sample flush & Time (50 sec), speed (+/- rpm)-48 \\
\hline Read delay & Time (15 sec), speed (+/- rpm)-20 \\
\hline
\end{tabular}

ICP-MS Instrumental Operating Conditions

where:

- THQ = Target hazard quotient

- $\mathrm{EF}=$ Exposure frequency

- ED = Exposure duration equiva lent to averge life time (70)

- $\mathrm{FI}=$ Food mean ingestion rate

- MC = Metal concentration in the samples $\left(\mu \mathrm{g} \mathrm{L}^{-1}\right)$

- AT = Average exposure of life time (365 days/year x 70 years)

- $\mathrm{BW}=$ average body weight (66.5 kg)

The RfD (reference oral doses) used were $3 \times 10^{-4}, 3 \times 10^{-3}, 5 \times 10^{-3}$, and $1.5 \mathrm{mg} / \mathrm{kg} /$ day for As, U, Mo, and $\mathrm{Cr}$, respectively (15).

The hazard index (HI) is the sum of the singular target hazard part of the elements assessed. The health risks associated were evaluated according to:

$\mathrm{HI}=$ Total THQ = THQ (As) + THQ (Cd) + THQ (Pb)
Accordingly, the THQ value below 1 indicates that there is no adverse effect to human health. However, if the HI is $>1$, there is the potential for carcinogenic health effects.

\section{Statistical Analysis}

All analyses were measured in triplicate and the data reported as the means \pm standard deviation. To identify the relationship between heavy metals in the samples, statistical analyses (variance and multiple comparisons) were performed using SPSS V. 25 software (SPSS Inc., Chicago, IL, USA).

\section{RESULTS AND DISCUSSION}

\section{Results of Analytical Methods}

The developed analytical method was subjected to validation by calculating the specificity, linearity, limits of detection and quantifica- 


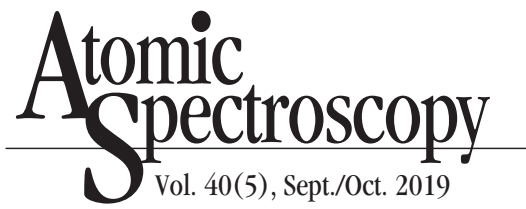

tion, precision and accuracy. The analytical curves showed good linearity within the working range (1-50 $\mu \mathrm{g} \mathrm{L}^{-1}$ ), with $\mathrm{R}^{2}$ values higher than 0.9990 . Three injections were done at each of the seven concentration levels for metals. The LOD was estimated as three times the standard deviation, which was reproduced from 10 analyses of the lowest calibration level standard. The LOQ was calculated by multiplying the standard deviation of 10 analyses of the lowest calibration level standard for 10 times. The LODs for the elements studied were from 0.02 to $2.81 \mu \mathrm{g} \mathrm{L}^{-1}$. The relative standard deviation (\%RSD) ranged between 1.3 and $3.1 \%$. Table II shows the mean data, and the results are consistent with the literature values (9). Repeatability of the method was calculated as the relative standard deviation (RSD) of 10 replicates of the sample, spiked with a relevant analyte. Acceptable $\%$ RSD values were obtained in this study (<3.1).

The spiking was performed by using the CRM 1640A Natural Mineral Water, and the calibration standards of the 3 fortification levels for metals. For sensitivity analysis, the solutions were spiked with low (1 $\left.\mu \mathrm{g} \mathrm{L}^{-1}\right)$, middle $\left(15 \mu \mathrm{g} \mathrm{L}^{-1}\right)$, and high concentrations $\left(40 \mu \mathrm{g} \mathrm{L}^{-1}\right)$, and studied by the suggested method. The results were between 89 and $109 \%$ for $1 \mu \mathrm{g} \mathrm{L} \mathrm{L}^{-1}, 86 \%$ and $103 \%$ for $15 \mu \mathrm{g} \mathrm{L}^{-1}$, and $85 \%$ and $103 \%$ for $40 \mu \mathrm{g} \mathrm{L}^{-1}$, and are also listed in Table III. The recovery values of the spiked values were found to agree with the literature values (16).

\section{Chemical Parameters}

Table IV shows the values of the physicochemical parameters $(\mathrm{pH}$ and conductivity) in the water samples. The $\mathrm{pH}$ level of the samples and the conductivity values varied from $6.2-8.3$ and $20-240 \mu \mathrm{sm}^{-1}$, respectively. The concentrations of the heavy metals in the water sam-
TABLE II

Results of Analytical Methods

\begin{tabular}{llcccc}
\hline Elements & Regression Equation & $\begin{array}{c}\text { Linear } \\
\text { Range } \\
\left(\mu \mathrm{g} \mathrm{L}^{-1}\right)\end{array}$ & $\begin{array}{c}\text { LOD } \\
\left(\mu \mathrm{g} \mathrm{L}^{-1}\right)\end{array}$ & $\begin{array}{c}\text { LOQ } \\
\left(\mu \mathrm{g} \mathrm{L}^{-1}\right)\end{array}$ & $\begin{array}{c}\text { RSD } \\
(\%)\end{array}$ \\
\hline As & $\mathrm{y}=1107.1 \mathrm{x}-181.45$ & $1-50$ & 0.04 & 0.12 & 1.3 \\
$\mathrm{~Pb}$ & $\mathrm{y}=14469 \mathrm{x}+5526.9$ & $1-50$ & 0.07 & 0.22 & 2.0 \\
$\mathrm{Cd}$ & $\mathrm{y}=1423.4 \mathrm{x}-398.85$ & $1-50$ & 2.81 & 9.35 & 3.1 \\
$\mathrm{Cs}$ & $\mathrm{y}=20998 \mathrm{x}-5876.4$ & $1-50$ & 0.02 & 0.08 & 0.9 \\
$\mathrm{Rb}$ & $\mathrm{y}=10029 \mathrm{x}+1720.9$ & $1-50$ & 0.06 & 0.19 & 1.9 \\
$\mathrm{Tl}$ & $\mathrm{y}=20086 \mathrm{x}-4326.2$ & $1-50$ & 0.07 & 0.23 & 2.7 \\
$\mathrm{Co}$ & $\mathrm{y}=7913 \mathrm{x}-1785.9$ & $1-50$ & 0.06 & 0.20 & 2.1 \\
$\mathrm{Cr}$ & $\mathrm{y}=6075.1 \mathrm{x}-732.95$ & $1-50$ & 0.08 & 0.28 & 2.6 \\
$\mathrm{Ga}$ & $\mathrm{y}=7369.6 \mathrm{x}-1308.9$ & $1-50$ & 0.07 & 0.23 & 2.3 \\
$\mathrm{~V}$ & $\mathrm{y}=7031.7 \mathrm{x}-2073.2$ & $1-50$ & 0.05 & 0.15 & 1.6 \\
$\mathrm{Ag}$ & $\mathrm{y}=6525.6 \mathrm{x}-1468.3$ & $1-50$ & 2.80 & 9.33 & 1.8 \\
$\mathrm{U}$ & $\mathrm{y}=34224 \mathrm{x}-5151$ & $1-50$ & 0.04 & 0.13 & 1.4 \\
$\mathrm{Th}$ & $\mathrm{y}=23429 \mathrm{x}-42381$ & $1-50$ & 0.08 & 0.27 & 2.8 \\
$\mathrm{Mo}$ & $\mathrm{y}=2325.2 \mathrm{x}-33.672$ & $1-50$ & 0.09 & 0.31 & 3.1 \\
\hline
\end{tabular}

TABLE IV

Some Physicochemical

Spike Recovery Values (\%) of the Elements

\begin{tabular}{|c|c|c|c|}
\hline $\begin{array}{l}\text { Ele- } \\
\text { ment }\end{array}$ & $\begin{array}{r}\text { Rec } \\
\text { Minimun } \\
\left(1 \mu \mathrm{g} \mathrm{L}^{-1}\right)\end{array}$ & $\begin{array}{l}\text { covery Valı } \\
\text { (15edium L L } \\
(15)\end{array}$ & $\begin{array}{l}\text { Maximum } \\
\left(40 \mu \mathrm{g} \mathrm{L}^{-1}\right)\end{array}$ \\
\hline Cs & $91 \pm 0.8$ & $87 \pm 1.5$ & $86 \pm 0.9$ \\
\hline $\mathrm{Rb}$ & $98 \pm 1.9$ & $91 \pm 2.3$ & $87 \pm 1.9$ \\
\hline $\mathrm{Tl}$ & $88 \pm 2.5$ & $87 \pm 2.8$ & $91 \pm 1.0$ \\
\hline Co & $94 \pm 2.0$ & $90 \pm 1.5$ & $88 \pm 1.0$ \\
\hline As & $97 \pm 2.8$ & $90 \pm 1.6$ & $89 \pm 0.6$ \\
\hline $\mathrm{Cr}$ & $109 \pm 2.8$ & $89 \pm 1.2$ & $88 \pm 1.3$ \\
\hline $\mathrm{Pb}$ & $108 \pm 2.2$ & $87 \pm 1.7$ & $85 \pm 0.6$ \\
\hline Ga & $98 \pm 2.3$ & $87 \pm 1.4$ & $86 \pm 1.6$ \\
\hline V & $98 \pm 0.9$ & $86 \pm 1.7$ & $85 \pm 1.1$ \\
\hline Ag & $93 \pm 1.7$ & $89 \pm 1.0$ & $88 \pm 1.0$ \\
\hline $\mathrm{Cd}$ & $94 \pm 2.9$ & $87 \pm 1.3$ & $86 \pm 0.7$ \\
\hline $\mathrm{U}$ & $89 \pm 1.3$ & $86 \pm 1.0$ & $92 \pm 2.6$ \\
\hline Th & $95 \pm 3.6$ & $94 \pm 2.0$ & $102 \pm 1.2$ \\
\hline Mo & $99 \pm 3.1$ & $103 \pm 2.1$ & $103 \pm 1.4$ \\
\hline
\end{tabular}

ples depend on physicochemical parameters of water, such as conductivity, $\mathrm{pH}$, salinity, turbidity, and total dissolved solids. It is well known that the solubility of heavy metals increases with an decrease in $\mathrm{pH}$. The conductivity value,
Parameters of Bottled Spring Water

Samples

\begin{tabular}{lcr}
\hline Brands & pH & $\begin{array}{r}\text { Conduc } \\
\text { tivity } \\
\left(\mu \mathrm{cm}^{-1}\right)\end{array}$ \\
\hline Brand 1 & 6.3 & 66 \\
Brand 2 & 7.9 & 135 \\
Brand 3 & 8.3 & 184 \\
Brand 4 & 6.7 & 20 \\
Brand 5 & 7.4 & 228 \\
Brand 6 & 7.3 & 122 \\
Brand 7 & 7.1 & 125 \\
Brand 8 & 7.8 & 164 \\
Brand 9 & 8.3 & 240 \\
Brand 10 & 7.9 & 98 \\
Brand 11 & 7.5 & 146 \\
Brand 12 & 6.2 & 46 \\
Brand 13 & 6.3 & 20 \\
Brand 14 & 6.8 & 240 \\
Brand 15 & 7.8 & 235 \\
Brand 16 & 6.9 & 115 \\
Brand 17 & 6.3 & 46 \\
Brand 18 & 7.1 & 134 \\
Brand 19 & 6.9 & 63 \\
Brand 20 & 7.1 & 177 \\
Brand 21 & 6.2 & 53 \\
Brand 22 & 6.4 & 71 \\
\hline & & \\
\hline
\end{tabular}


which is the level of water's ability to conduct an electric current, is related to the amount of dissolved minerals in water. This value does not give an indication of which element is present, but a higher value of conductivity is a good indicator of the presence of metals.

\section{Analysis of Toxic Elements in Samples}

The locations where the spring waters were obtained and bottled are shown in Figure 1 (black dots). Twenty-two bottled spring water samples with different brands and high consumption rates were analyzed by the proposed method. According to the results in Table V, cadmium, cesium, thallium, cobalt, lead, silver, and thorium were not found (<LOD) in the samples. However, arsenic, rubidium, gallium, vanadium, uranium, chromium, and molybdenum were found in some samples. The maximum amounts of $\mathrm{Rb}$, As, Cr, Ga, V, U, and Mo found in these sasmples were $1.8,8.5$, $8.5,0.8,1.0,2.1$, and $2.7 \mu \mathrm{g} \mathrm{L}^{-1}$, respectively. There was no correlation between the determined concentrations of the elements in the samples $(\mathrm{p}<0.05)$.

As reported in a European study (1), $0.44 \mu \mathrm{g} \mathrm{L}^{-1}$ lead, $519 \mu \mathrm{g} \mathrm{L}^{-1}$ cesium, $3.79 \mu \mathrm{g} \mathrm{L}^{-1}$ cobalt, 1010 $\mu \mathrm{g} \mathrm{L} \mathrm{L}^{-1}$ rubidium, $66 \mu \mathrm{g} \mathrm{\textrm {L } ^ { - 1 }}$ vanadium, $72.2 \mu \mathrm{g} \mathrm{L}^{-1}$ uranium, and 37.8 $\mu \mathrm{g} \mathrm{\textrm {L } ^ { - 1 }}$ molybdenum were detected in bottled spring water samples purchased at a local market. The results from the present study indicate that the metal content of the water samples studied here was very low com-pared to the above literature data.

In light of the results obtained from the present study, it can be stated that the metal levels in the bottled spring waters are below the WHO provisional guideline values and, therefore, bear no toxicological risk to the population. Consequently, the bottled spring water samples comply with official standards with respect to metal content (17).

\section{Results of Health Risk} Assessment

Dietary intake calculations were made based on the Development Bank of Turkey data reports. They list the average body weight for the Turkish population at $66.5 \mathrm{~kg}$, and spring water consumption for the population as $2 \mathrm{~L} /$ day.

In this study, the THQ of As, Cr, Mo, and $\mathrm{U}$ was determined as $8.5 \times 10^{-1}, 1.03 \times 10^{-6}, 1.6 \times 10^{-2}$, and $2.1 \times 10^{-2}$, respectively. The parame-

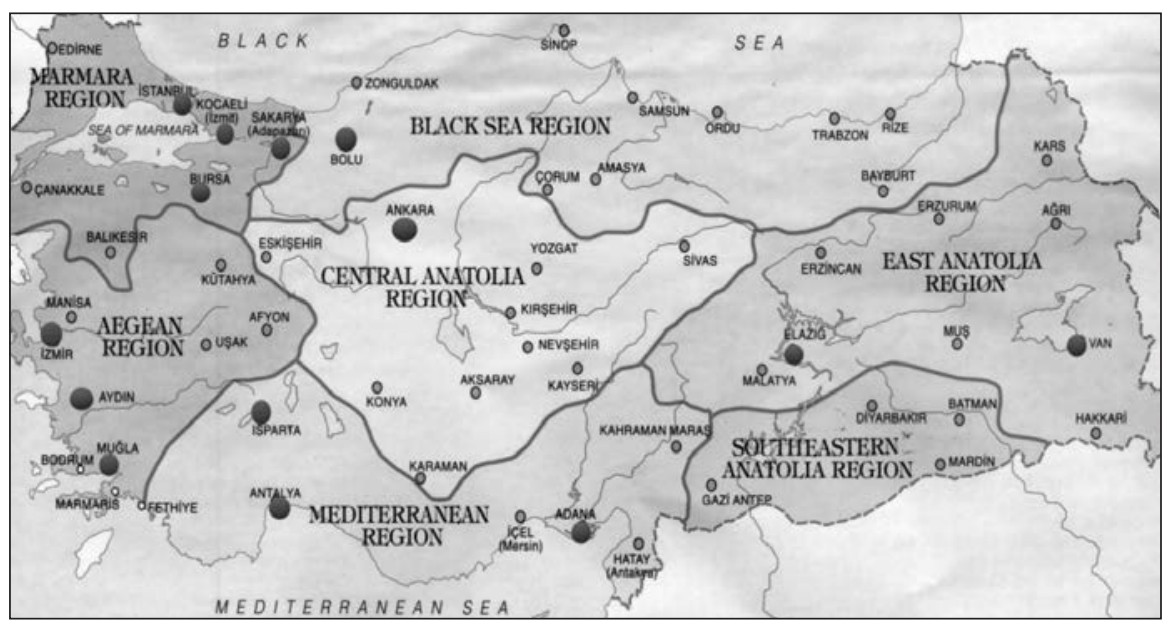

Fig. 1. Locations where studied spring waters were obtained and bottled (black dots). ters used for risk assessment give an estimation of the human risk evaluation of exposure to metal in the samples stated. The target hazard quotient (THQ) value of less than 1 indicates that there is no major risk of carcinogenic effects for the consumer. In this study, the hazard index (HI) value was 0.88 (18); thus there is no health risk due to metals contamination.

\section{CONCLUSION}

In this study, 22 different brands of bottled spring water were characterized in terms of the mass concentration of trace metals, $\mathrm{pH}$, and conductivity. It was found that the $\mathrm{pH}$ and conductivity levels of commercially available natural mineral water were at a maximum of 8.3 and $240 \mu \mathrm{sm}^{-1}$, respectively.

Also, an ICP-MS method was validated for the determination of toxic and trace elements in bottled spring water. The validated methodology proved to be fast, easy, and simple. It was possible to obtain precise and accurate results even at very low metal levels. The linearity, limits of detection and quantification, recovery and accuracy were also determined. Recovery values were determined to be over $85 \%$ for toxic metals, indicating adequate precision and accuracy of the analyses.

The trueness of the method and the performance of NIST 1640A natural water was satisfactory. According to the results of the spring water analysis, the elements $\mathrm{Cd}, \mathrm{Cs}$, $\mathrm{Tl}, \mathrm{Co}, \mathrm{Pb}, \mathrm{Ag}$, and Th were not determined in the samples, while $\mathrm{Rb}$, As, Cr, Ga, U, and Mo were detected in some samples. The parameters were found to be below WHO guideline values. The health risk assessment indices generally indicate that there is no risk of metals contamination to public health with the respective bottled mineral waters. However, it is very important that similar studies within 


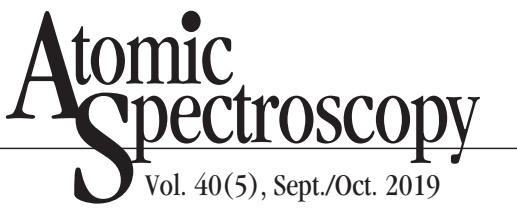

TABLE V

Element Composition $\left(\mu \mathrm{g} \mathrm{L}^{-1}\right)$ of Samples

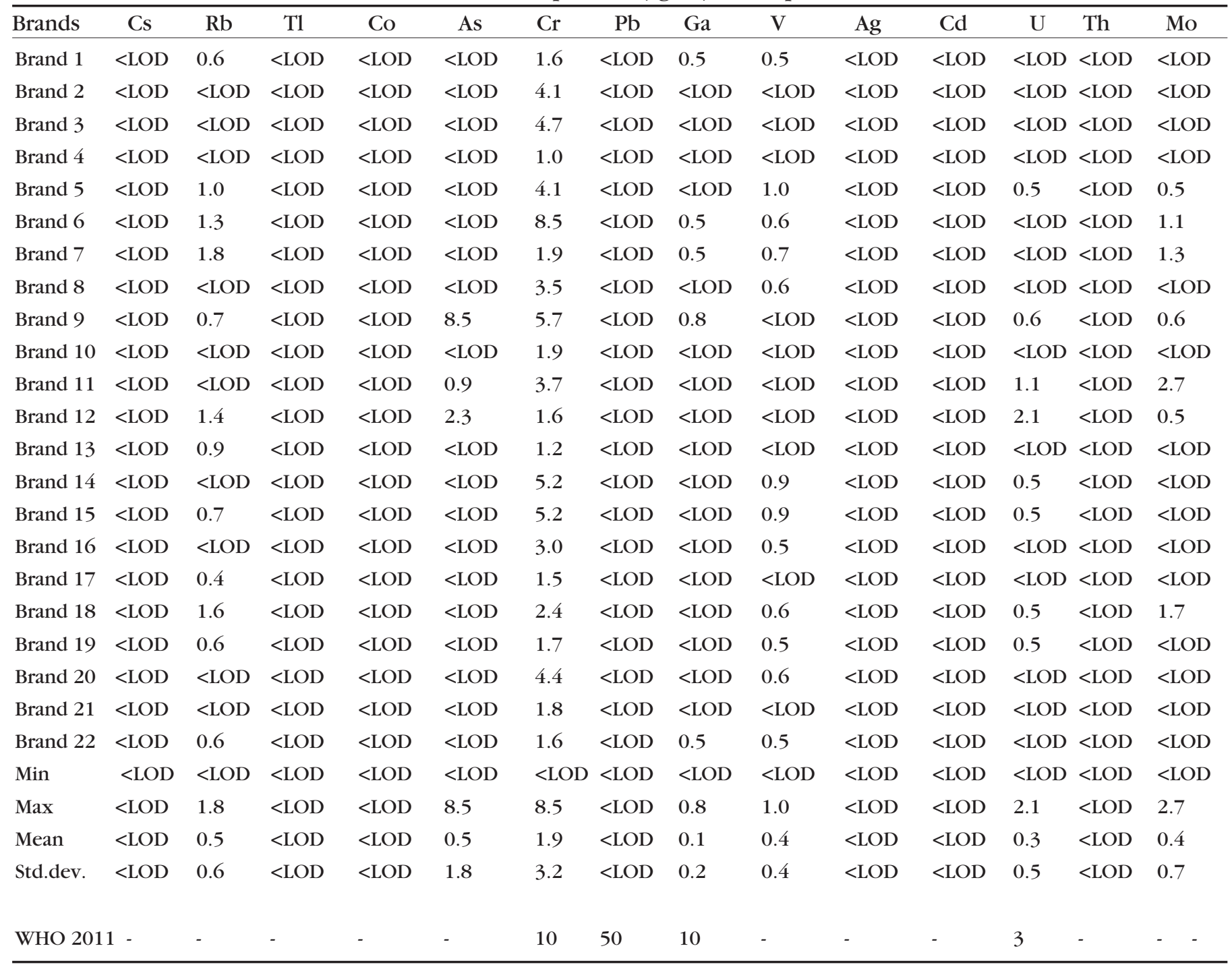

more extensive sampling should be repeated periodically to protect the public.

\section{ACKNOWLEDGMENT}

This study was financially supported by the Akdeniz University Scientific Research Projects Unit (Grand\#FBA-2019-4371).

Received June 18, 2019.

\section{REFERENCES}

1. D. Bertoldi, L.Bontempo, R. Larcher, G. Nicolini, S. Voerkelius, G.D. Lorenz, H. Ueckermann, $\mathrm{H}$. Froeschl, M.J. Baxter, J. Hoogewerff and P. Brereton, Journal of Food Composition and Analysis. 24(3), 376-385 (2011).

2. IARC, Inorganic and Organic Lead Compounds. IARC Monographs on the Evaluation of Carcinogenic Risks to Human. 87, 519 (2006).

3. S. Quattrini, B. Pampaloni and M.L. Brandi, Clin. Cases Miner. Bone Metab. 13(3), 173-180 (2016).
4. M.U. Khandaker, N.L.M. Nasir, N.S. Zakirin, H.A. Kassim, K. Asaduzzaman, D.A. Bradley, M.Y. Zulkifli and A. Hayyan, Radiation Physics and Chemistry 140, 173-179 (2017).

5. A. Baba, F.S. Erees, Ü. Hicsönmez, S. Çam, H.G. Özdılek, Environ. Monit. Assess. 139, 277-285 (2008).

6. A. Misunda, B. Frengstad, U. Sewersd and C. Reimanna, The Science of the Total Environment 243 (244), 21-41 (1999).

7. A. Astel, R. Michalski, A. Lyko, M.J. Czapla, K. Bigus, S. Szopa and A. 
Kwiecinska, Journal of Geochemical Exploration 143,136-145 (2014).

8. S. Kilic, S. Yenisoy-Karakas and M. Kilic, Food Analytical Methods 8, 2487-2495 (2015).

9. F. Gutierrez-Reguera, R. MontoyaMayor, I. Seijo-Delgado and M. Ternero-Rodríguez, Afinidad 73(574), 102-118 (2016).

10. S. Kilic, I.B. Cam, T. Tongur and M. Kilic, Journal of Food Science 83(10), 2675-2681 (2018).

11. Eurachem, The Fitness for Purpose of Analytical Methods: A Laboratory Guide to Method Validation and Related Topics, Upsala, Sweden, 75 (1998).

12. WHO, Chapter 6: Dietary Exposure Assessment of Chemicals in Food. Principles and Methods for the Risk Assessment of Chemicals in Food, Environmental Health Criteria (2009)

13. UNEP/FAO/WHO, Assessment of Dietary Intake of Chemical Contaminants, WHO/HPP/FOS/92.6, UNEP/GEMS/92.F2, United Nations Environmental Program, Nairobi, Kenya (1992).

14. USEPA United States Environmental Protection Agency, Risk-Based Concentration Table, U.S. Environmental Protection Agency, Washington, DC, USA (2009).

15. USEPA, Risk Based Concentration Table. Retrieved from https://www.epa.gov.reg3hwmd/ risk/human/index.htm (2013).

16. S. Kilic, M.F. Cengiz, and M. Kilic, Environmental Monitoring and Assessment 190, 202 (2018).

17. WHO, Guidelines for DrinkingWater Quality. World Health Organization, Fourth Edition, 564 (2011).

18. FAO/WHO, Food Consumption and Exposure Assessment of Chemicals. Report of FAO/WHO Consultation WHO, Geneva, Switzerland, pp. 17-25 (1997). 